\title{
Advancing Aquatic Ecosystem-Based Management with Full Consideration of the Social-Ecological System
}

\author{
Gerjan Piet, Gonzalo Delacámara, Marloes Kraan, Christine Röckmann, \\ and Manuel Lago
}

\begin{abstract}
In this study we present an integrated Ecosystem-Based Management (EBM) approach that attempts to reconcile several concepts including integrated ecosystem assessment (IEA), marine spatial planning, resilience thinking, and complex adaptive systems. The approach builds on the IEA process but enhances it by explicitly considering the full social-ecological system (SES) and the creation of a generic framework for assessment of ecosystem status and management strategy evaluation.
\end{abstract}

\section{Lessons Learned}

- This approach reconciles many existing concepts that describe the ecological system, the social (or socio-economic) system and EBM into a unifying approach

- It consists of concrete steps which identify issues for the practitioner to consider, gives examples that provide the basis for a common framework,

- It provides guidance on how to make the framework (more) operational and is applicable to any aquatic ecosystem

G. Piet $(\bowtie)$

Wageningen Marine Research, IJmuiden, The Netherlands

e-mail: gerjan.piet@wur.nl

G. Delacámara

IMDEA Water Institute, Alcalá de Henares, Madrid, Spain

M. Kraan

Wageningen Marine Research, IJmuiden, The Netherlands

Environmental Policy Group, Wageningen University, Wageningen, Netherlands

C. Röckmann

Wageningen Marine Research, IJmuiden, The Netherlands

Wageningen Economic Research, The Hague, The Netherlands

M. Lago

Ecologic Institute, Berlin, Germany

(C) The Author(s) 2020

T. G. O'Higgins et al. (eds.), Ecosystem-Based Management, Ecosystem Services and Aquatic Biodiversity, https://doi.org/10.1007/978-3-030-45843-0_2 
- It allows the incorporation and synthesis of interdisciplinary information on SES into practical and useful linkage frameworks for EBM plan development and implementation

\section{Needs to Advance EBM}

- Where consideration of the full SES can be overwhelmingly complex leading to inaction, we propose to work with a subsection of the SES (called subSES). This subSES can then be the starting point for building the knowledge base for EBM decision making. We provide practical guidance how to construct such a knowledge base for both the ecological and the social system.

- The subSES, in conjunction with the available knowledge base, then drives the development of the knowledge base and determines the type of risk assessment(s) that can be applied. Science should then inform the process to translate the high-level societal goals into operational objectives, identify the main barriers that prevent achievement of these objectives, and guide the relevant authorities that develop an EBM plan.

- A novel component of this approach is that the EBM plan distinguishes between management measures (interacting with the ecological system) and policy instruments (interacting with social processes) that together harness the knowledge base of the subSES.

\section{Introduction}

Conventional management of aquatic resources, based on a specific policy or directed to a sub-sector or flagship species, has often failed to deliver on the policy objectives (Long et al. 2015). As an alternative, Ecosystem-Based Management (EBM), which has a more holistic understanding of the ecosystem and its linkages, is widely accepted as the key concept to guide contemporary decision-making (Börgstrom et al. 2015; Cormier et al. 2017). The conventional management perspectives have assumed, either implicitly or explicitly, that effective policy making is hindered by lacking or inadequate knowledge of ecological processes, functions, and services (Ruckelshaus et al. 2009). Such an ecological focus has failed to produce the full picture of best available knowledge for effective decision-making (Christie 2011). Cormier et al. (2017) distinguish decision-making, which is essentially a specific choice among alternatives, from policy-making, which is a process of identifying a problem and setting societal goals and objectives. In practice, the policy is implemented through a management plan expected to 'carry into effect' the policy objective. An effective policy cycle requires the incorporation of social and institutional processes, such as the involvement of various institutional actors (Röckmann et al. 2015) and an understanding of the governance context (Bissix and Rees 2001). The need for a more holistic approach that incorporates ecological and 
socio-economic factors (Bianchi 2008), however, can result in in-action due to overwhelming complexity (DeFries and Nagendra 2017).

As a paradigm, EBM addresses uncertainty and complexity, it is an interdisciplinary visioning of multiple objectives, and as such, EBM can be categorised as a 'wicked problem' (Berkes 2012). 'Wicked problems' have no definitive formulation, no clear stopping rule and no objectively right or wrong solutions and no final resolution (Rittel and Webber 1973); (Ludwig 2001). DeFries and Nagendra (2017) suggest the following solutions for addressing wicked problems: multi-sectoral decision-making; institutions that enable management to span across administrative boundaries; adaptive management; markets that incorporate natural capital; and collaborative processes to engage diverse stakeholders and address inequalities. Integrating environmental and socio-economic processes (including institutional, ethical and cultural) requires a single conceptual framework (Christie 2011). The concept of social-ecological systems (SES) can provide such a framework (De Lange et al. 2010). This SES can be split into smaller social-ecological sub-systems (subSES) to address the issue of complexity.

Relevant information and processes can be considered in individual compartments that form the SES. Applying the concept of SES in aquatic EBM implies that any distinction between social and natural systems is artificial and arbitrary by definition, because they are connected (Berkes 2012).

Socio-Ecological Systems can be considered complex adaptive systems (CAS) (De Lange et al. 2010) as the structure, functions, and dynamics of CAS emerge from the interaction and connectedness of the system's constituent parts and with other systems (Hagstrom and Levin 2017). By acknowledging that SES are CAS, management can overcome the drawbacks of conventional approaches. Instead of searching for optimal solutions, linear dynamics, or marginal changes under complete information, a shift towards a more dynamic management approach can be made, where non-linear changes, uncertainty, and surprise are intrinsic characteristics of the system. In addition to the known unknowns, e.g., lack of historic data of species, CAS come with new uncertainties that cannot be tackled through standard sensitivity analysis (Polasky et al. 2011).

Sustainability is among the ultimate objectives of EBM (Long et al. 2015). Ostrom (2009) identified four core subsystems of SES sustainability: (1) resource systems; consisting of (2) resource units; (3) governance systems; and (4) users. When modelling a SES, it may be worth distinguishing these subsystems. In the face of ongoing changes and their uncertain consequences as well as exposure to uncertain shocks, the key to sustainability is enhancing the resilience of a SES (Folke et al. 2005; Nelson et al. 2006; Biggs et al. 2015). Enhancing resilience in terms of persistence, adaptability and transformability (Folke et al. 2010) means preserving the SES's adaptive capacity in order to remain within a certain range of conditions that meet the sustainability goals. Resilience thinking promotes governance frameworks that are able to reconcile the conflicting interests and visions of different stakeholders in a transparent and accountable way so as to foster cooperation among them and enhance stakeholders' ability to commit to legitimate and transparent policy objectives (Dietz et al. 2003). In addition, these governance frameworks 
should also pave the way to achieve collectively agreed goals through robust institutions, with stakeholders who are able to regularly adjust to changes in the ecological and the social-economic systems (Nelson et al. 2006).

Linkage frameworks such as DPSIR, Driver-Pressure-State-Impact-Response (OECD 1994; EEA 1995; Elliott 2002), are commonly used in the context of environmental management to describe how human activities impact the state of the ecosystem (Halpern et al. 2008; Knights et al. 2013) and hence the supply of ecosystem services to human well-being (Elliott et al. 2017). Linkage frameworks rely on accurate descriptions of linkages (e.g., stressor-receptor or pressure-state relationships) and can be informed by qualitative, quantitative, or expert judgementbased assessments, or any combination of these (Knights et al. 2014). Such linkage frameworks have been applied in an EBM context to guide the selection of management measures and their evaluation using risk-based approaches (Knights et al. 2015; Piet et al. 2015; Borgwardt et al. 2019; Teixeira et al. 2019; Culhane et al. 2019).

Few, if any, examples of EBM planning initiatives informed by advanced science have been implemented across multiple sectors (Katsanevakis et al. 2011; Cormier et al. 2017). In order to enhance the use of salient science (Röckmann et al. 2015) into the policy-making process, Cormier et al. (2017) proposes four steps: strategic goal setting; tactical objectives; management measures; and adaptive management. Integrated ecosystem assessments (IEAs) have also been proposed as a tool to operationalise EBM as they provide a framework for organizing science in order to inform decisions in marine EBM at multiple scales and across sectors (Levin et al. 2009a; Walther and Möllmann 2014; Tallis et al. 2010; Harvey et al. 2017). It is therefore not surprising that the IEA process described by (Levin et al. 2009b) is closely aligned to the EBM processes described by Börgstrom et al. (2015) or Ansong et al. (2017). The (further) development and operationalization of an IEA/EBM approach is however hindered by the lack of a systematic, critical appraisal.

In this study, we merge the existing IEA and EBM processes into a single generic approach that can be applied in all aquatic systems. This approach is then enhanced by explicitly considering the full social-ecological system (SES), which incorporates both environmental and socio-economic processes (Christie 2011). In order to advance this process, we provide the systematic criteria that allow critical appraisal of its progress based on the aspects of EBM, identified in the review by Long et al. (2015) together with additional practical guidance that emerges from concepts such as resilience thinking and CAS. Further, we provide operational guidance on the development of relevant subSES to inform this approach. 


\section{Advancing EBM}

EBM should be able to guide decision-makers by identifying trade-offs between societal goals (Walther and Möllmann 2014). These trade-offs may involve the choice between the conservation goals of specific ecological components (Aanesen et al. 2014), between ecological and socio-economic objectives (ICES 2017), between different ecosystem services (Turkelboom 2017; Dick 2017), or the conflicting interests of specific stakeholders. While decision-making is often primarily aimed at effectively achieving specific conservation goals it ultimately involves socio-economic considerations including: (1) the sharing of costs and benefits among stakeholders; (2) the balance between short- and longer-term benefits; (3) the need to forgo current rents in exchange for future security; and (4) local opportunity costs and regional and global benefits.

EBM should be considered an incremental process as opposed to a single, giant leap away from traditional management (DeFries and Nagendra 2017; Borgstrom et al. 2015). As EBM revolves around a cyclical process, advancements can be made with every iteration of the adaptive management cycle. In this study, we adopt the IEA process and enhance earlier frameworks by incorporating the SES concept

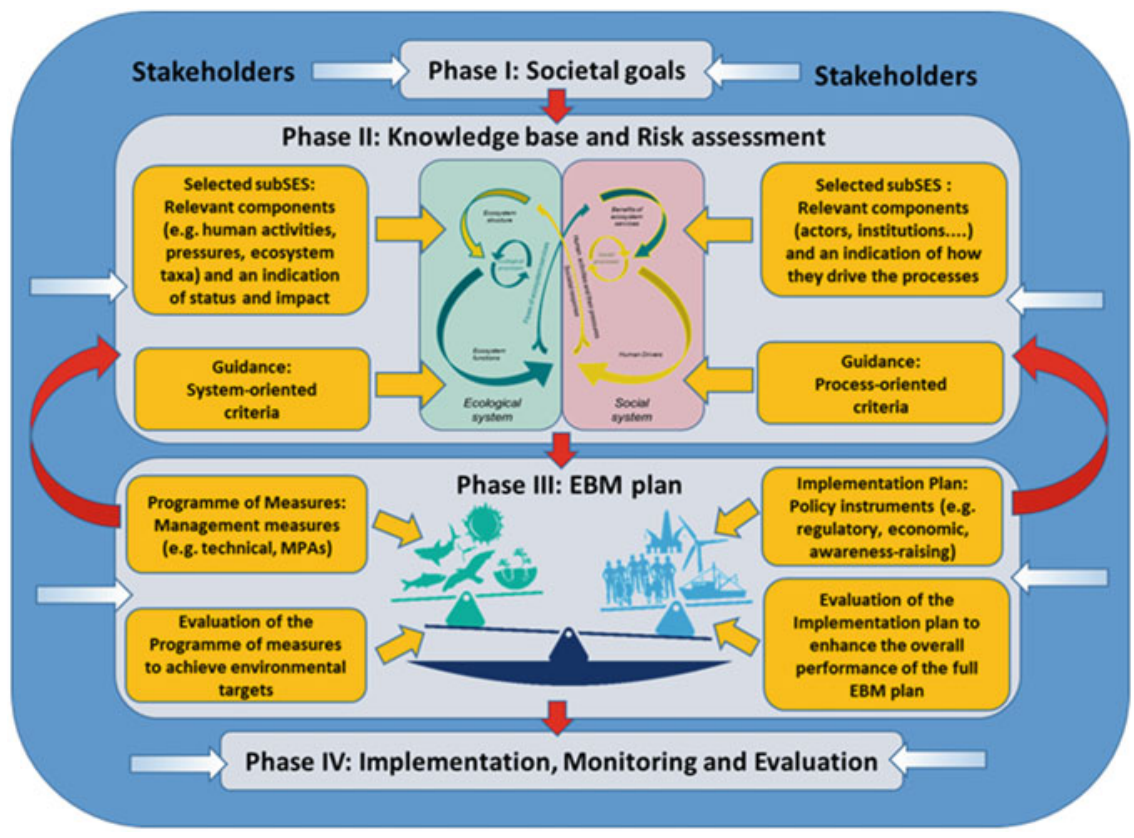

Fig. 1 One cycle of the adaptive, cyclical ecosystem-based management approach built around a balanced representation of the selected social-ecological sub-system (subSES). The figure depicts the phases occurring in the science domain (identified in Fig. 2) but identifies where in each phase cross-domain interaction occurs (i.e., stakeholder involvement) with the wider society. In each phase, the main contributions of this study to advance EBM are indicated 
(Fig. 1) to shape the knowledge base and by providing practical guidance that allows an appraisal of progress. We assess progress in developing the knowledge base by looking at the key principles of EBM according to Long et al. (2015) and their alignment to relevant concepts such as IEA (Levin et al. 2009b; Samhouri et al. 2014), wicked problems (DeFries and Nagendra 2017), EBM phases (Borgstrom et al. 2015), policy-making processes (Cormier et al. 2017), ecosystem-based marine spatial planning (Ansong et al. 2017), and resilience thinking (Folke et al. 2010). We build a common framework around these concepts and organise them into four operational phases (identification of societal goals; developing the knowledge base and risk assessments; EBM plan development; implementation, monitoring, and evaluation), which differ in the scientific expertise required.

\subsection{Phase I: Identification of Societal Goals}

Phase I involves the scoping of societal goals, policy objectives, and perceived threats form the starting point of the IEA (Levin et al. 2009b, 2014) and EBM (Ansong et al. 2017; Cormier et al. 2017). It includes the analysis of policy synergies, conflicts, and an understanding of opportunities and challenges for developing EBM alternatives as well as stakeholder participation to help identify and prioritise among them. A possible issue is that policy objectives, mostly applying to global or regional scales, often refer to conditions of the ecological system only while at the local level, the objectives often aim to restore the sustainability of the whole SES. This may require reconciling objectives at different scales.

\subsection{Phase II: Setting up the Knowledge Base and Conducting a Risk Assessment}

Phase II builds on the inventory of societal goals in the previous phase and identifies relevant social-ecological sub-systems (subSES), similar to the 'focal SES' (Ostrom 2009). Such subSES should consist of one or more linkages in the linkage framework tied to one or more societal goals and are the basis to elaborate those subSES into what is to become the EBM knowledge base (Fig. 2), and which may contain both qualitative and/or quantitative information. The linkage framework is constructed using consistent typologies of the activities, their pressures and the ecosystem components affected by them (see e.g. Knights et al. 2015; Borgwardt et al. 2019) and with categories that resonate with stakeholders. If needed hierarchical typologies can be applied. For example the activity 'fishing' can be divided into specific types of fishing (e.g. demersal or pelagic) or an ecosystem component can be divided into functional groups or even species. The application of the linkage framework should ascertain that those subSES cover all the elements that matter to 


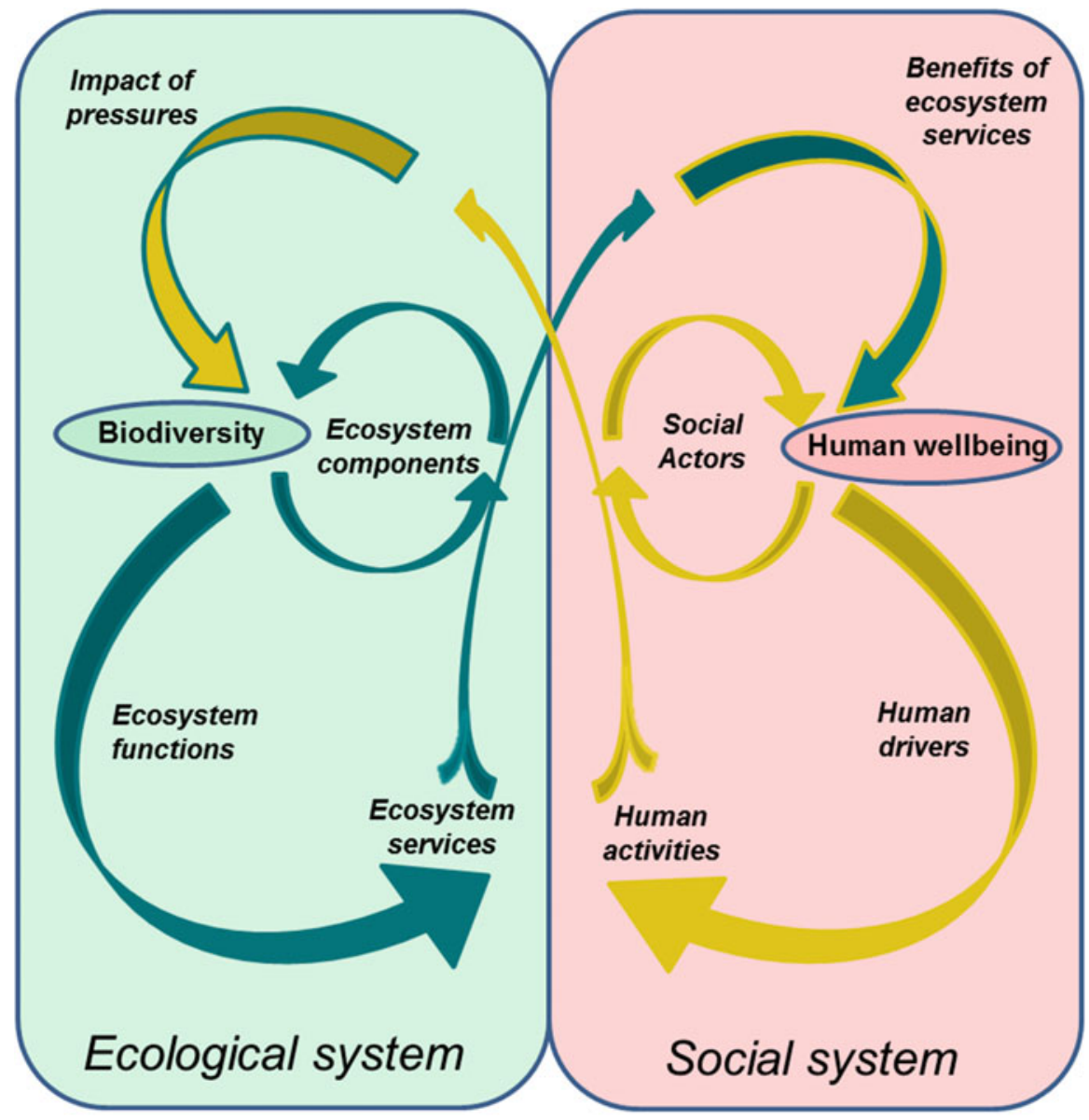

Fig. 2 The social-ecological system (adopted and modified from (Gómez et al. 2016)) consisting of an ecological system-based supply-side where the flow of ecosystem services into the social system contributes to human well-being and a social-system-based demand-side where the human activities and their pressures impact the ecosystem components and their functioning

the problem identified in Phase I, as well as any additional issues that have emerged through stakeholder consultation. Note, however, that with the introduction of more detailed categories, the complexity of the linkage framework (i.e. number of linkages) and thus information demand increases.

Different types of data, generally covering different subSES, are to be used in EBM phases II and III. Information on SES complexity is a requirement for diagnosing why some SES are sustainable while others are not (Ostrom 2009). Therefore, the inherent complexity of the SES and subSES should be harnessed, rather than eliminated. In practice, this implies that different subSES can be analysed at the appropriate level of detail without being hindered by the complexities and 
requirements of the full SES. At the same time the full SES, in which this subset operates, helps with interpretation of the outputs and their communication to stakeholders.

Table 1 provides a suite of system-oriented criteria to determine the suitability of the (sub)SES knowledge base to describe the ecological system and guide EBM. A similar list of process-oriented criteria for the social system is given in Table 2. As IEA/EBM is supposed to be an adaptive process, the aim is to gradually improve the knowledge base of the ecological system or the institutional set-up of the social system against those criteria in each of the subsequent iterations of the EBM cycle.

With the structure of the knowledge base established, we can consider the three IEA steps: (1) development of ecosystem indicators; (2) identification of reference levels; and (3) conducting risk analyses (Levin et al. 2014). For risk analysis, we suggest to consider the Environmental Risk Assessment (ERA) approach, which distinguishes the different levels of risk analyses and classes of system complexity (Holsman et al. 2017). Level 1 of the ERA consists of a qualitative evaluation that is often based on expert opinion. Level 2 consists of semi-quantitative ERAs based on estimates of exposure and severity, and Level 3 consists of fully quantitative assessments based on a mechanistic understanding of the system (see Holsman et al. (2017) and Stelzenmüller et al. (2015) for additional examples). The complexity of the system can be described using three nested classes. Class 1 encapsulates the direct impact of a single pressure on a given social or ecological subject (e.g., bottom trawl fisheries catching cod). Class 2 measures the direct and indirect effects of a single pressure on multiple interacting subjects (e.g., fishing impacts on ecosystems as in (Hobday et al. 2011)) or the effects of multiple pressures on a single subject. Class 3 refers to the direct and indirect effects of multiple interacting pressures on multiple interacting subjects (e.g., bottom trawl fishing, dredging and contaminants affecting the seabed habitats and the fish foraging there).

It is important to distinguish between the overall, less detailed ERA of the whole SES and the detailed ERAs conducted on the subSES. Within the overall ERA of the whole SES, the qualitative or semi-quantitative ERAs of the full SES (i.e., Class 3) can be used to identify the linkages that introduce the greatest risk to the ecosystem (aligned to the threats in Phase I). These Level 1 or 2 ERAs are primarily aimed at guiding decision makers on which sector-specific management measures to focus (Cormier et al. 2017).

The levels of risk analyses and classes of system complexity described above determine the type of ERA required. Formal description of the SES, through a linkage framework, can provide further characterisation of the classes. This linkage framework can then also be used to assess the quality of the ERA for each level of the analytical tools. Ultimately, the aim is to advance from a qualitative ERA towards an increasingly quantitative ERA that is more elaborate and realistic in terms of the 'reciprocal and cumulative interactions among multiple (interacting) pressures and multiple interacting subjects' (Holsman et al. 2017) that make up the full SES. Distinguishing the subSES and the full SES, each with complementary ERAs can reduce the level of complexity in order to ensure salient information into the policy cycle (Folke et al. 2005; Biggs et al. 2015). 
Table 1 Ecological EBM criteria based on the EBM principles in Long et al. (2015) for assessing the knowledge base of the ecological part of the social-ecological system (SES) and hence the core sustainability SES subsystems: resource systems and resource units (Ostrom 2009). Guidance is provided to assess to what extent the knowledge base has advanced in order to support EBM. Links to other criteria in this table or Table 2 are in italics

\begin{tabular}{l|l}
\hline EBM criteria & Generic assessment guidance and considerations \\
\hline Ecological integrity and & This can be achieved by defining and conserving a diversity of
\end{tabular}
biodiversity species traits or functional groups that support the integrity of the ecosystem, or check the three aspects: variety; balance; and disparity. Are these explicitly considered in the knowledge base?

The ecological structural components determine the functioning of the ecological system. Hence the link to the 'Consider ecosystem connections' criterion: a knowledge base that covers more relevant components or detail is better.

\begin{tabular}{|l|l}
\hline Consider ecosystem & This is determined by the ecological part of the SES (e.g., by
\end{tabular} connections $\quad$ mapping critical connections) and is linked to the 'Ecological integrity and biodiversity' criterion as more components and/or detail increase this aspect (e.g., in terms of taxa considered in the food web) this can be improved with an indication of the importance of a connection (e.g., pressure-state relationships, predatorprey relationships). Knowledge on the ecological functioning of the ecological structural components determines the provisioning of ecosystem services which contribute to human well-being and as such can be incorporated into (economic) markets.

Account for dynamic nature Variation in the ecological part of the SES (e.g., due to perturof ecosystems bations) should be considered. Longer time-series are better. Question the assumption of perfect foresight. Include exogenous scenarios of socio-economic drivers or environmental change (e.g., climate scenarios). Strengthen feedbacks that maintain desired regimes, break or disturb feedbacks that maintain undesired regimes; look for non-linearity in the system as these are often the cause for the dynamic nature.

\begin{tabular}{|l|l}
\hline Acknowledge uncertainty & This requires transparency on the quality of the knowledge base
\end{tabular} which could be reflected, for example, through the assessment of uncertainties, reporting of crucial (model) assumptions and confidence intervals in the output. Uncertainty is inherent to complex adaptive systems (such as the marine) and their management. In addition to the known unknowns (e.g., lack of historic data of species), complex systems come with new uncertainties that cannot be tackled through standard sensitivity analysis (Polasky et al. 2011). The social EBM criteria 'Adaptive management' and 'stakeholder participation' (see Table 2) become increasingly important if uncertainty in the current knowledge base is high.

Appropriate spatial and tem- What are the appropriate spatial and temporal scales of the (eco) poral scales system? For example, resolution of spatial grid and temporal units (e.g., years, months). Which scales to consider? Not just spatial/ temporal but also in different domains (e.g., ecological, jurisdictional, administrative or political). Use a systems framework to address relevant scales and how they interact. Assessment should occur at the ecosystem scale. If other scales are relevant and do not match with the ecosystem scale this needs to be identified. 
Table 1 (continued)

\begin{tabular}{l|l}
\hline EBM criteria & Generic assessment guidance and considerations \\
\hline Distinct boundaries & $\begin{array}{l}\text { Acknowledge boundaries and thus the fluxes and influences from } \\
\text { outside of the boundaries of the ecosystem. Consider both juris- } \\
\text { dictional boundaries as well as ecosystem boundaries (see } \\
\text { Appropriate Spatial and Temporal Scales). Are transboundary } \\
\text { issues considered? For example: Terrestrial run-off into rivers and } \\
\text { lakes or inflow of rivers into the coastal/marine ecosystem. The } \\
\text { definition of boundaries should allow the adaptation of institu- } \\
\text { tions in a good social-ecological fit (see recognise coupled SES). }\end{array}$ \\
\hline Recognise coupled SES & $\begin{array}{l}\text { Are all relevant flows considered between the social and the } \\
\text { ecological system that make up the SES? How many linkages, or } \\
\text { how much of the activities, pressures, ecosystem components and } \\
\text { the ecosystem services they provide is covered in the subSES } \\
\text { (used in the management strategy evaluation) compared to the full } \\
\text { SES. Is it understood how these link to the actors that drive the } \\
\text { relevant social processes (see Table 2)? }\end{array}$ \\
\hline Consider cumulative impacts & $\begin{array}{l}\text { Apply an integrated perspective, including all relevant activities } \\
\text { and their pressures acting on the ecosystem (see recognise } \\
\text { coupled SES). Consider whether synergistic or antagonistic } \\
\text { cumulative effects apply (Crain et al. 2008). }\end{array}$ \\
\hline
\end{tabular}

\subsection{Phase III: Planning of EBM}

This phase should result in a comprehensive EBM plan that can mitigate the threats and achieve the policy objectives identified in Phase I. In building a comprehensive EBM plan, the Phase II knowledge base is used to first guide the design of the EBM plan, and then evaluate the plan's potential performance before implementation in Phase IV.

Most examples of management plans have focused on ecological outcomes (e.g., Rademeyer et al. 2007; Ansong et al. 2017; Samhouri et al. 2014). Since EBM is concerned with the management of SES, the EBM plan that is developed and tested in this phase should cover both the ecological and social components of the system. To that end, the EBM plan consists of two interconnected, structured, yet differentiated sets of decisions, management measures, and policy instruments, each primarily addressing a specific aspect of the SES (see Fig. 3):

- Management measures are integrated into a Programme of Measures, a combined set of actions aimed at achieving environmental objectives and thus to enhance and protect the ecological system. Potential management measures can be classified according to the three ISO 31,000 risk management categories: prevention; mitigation; and recovery controls (Cormier et al. 2013, 2018) that can be aligned to the EBM management measure typology outlined in Piet et al. (2015), depending on where in the linkage framework the measure intervenes.

- Prevention controls manage the causes of the risk and are aimed at the human activity and/or the pressure. Examples are input control (e.g., scrapping schemes to reduce the capacity of the fishing fleet), output controls that 
Table 2 Social EBM criteria for assessing the knowledge base of the social part of the socialecological system (SES) and hence the core sustainability SES subsystems: governance systems and users (Ostrom 2009). These criteria are based on the key EBM principles identified by Long et al. (2015) and link to the relevant governance actors. Guidance is provided to assess to what extent the institutional set-up and its governance processes can support EBM. Links to other criteria in this table or Table 1 are in italics

\begin{tabular}{|c|c|c|}
\hline EBM criteria & Actors & Generic assessment guidance and considerations \\
\hline $\begin{array}{l}\text { Use of scientific } \\
\text { knowledge }\end{array}$ & \multirow[t]{3}{*}{ Science } & $\begin{array}{l}\text { This includes the scientific use of all types of knowledge } \\
\text { including local knowledge, traditional knowledge or citi- } \\
\text { zen science. Has the knowledge been produced according } \\
\text { to the scientific standards? Is the methodology appropri- } \\
\text { ate? Are procedures transparent? Peer-reviewed? Is there } \\
\text { consensus on the quality of the available (scientific) } \\
\text { knowledge? This requires both the interaction between } \\
\text { scientists and decision-makers to foster salience in scien- } \\
\text { tific input as well as the interaction between scientists and } \\
\text { other actors to foster credibility in knowledge production } \\
\text { (see Röckmann et al. 2015). Ultimately the outcome of the } \\
\text { process should be perceived as evidence-based. }\end{array}$ \\
\hline Inter-disciplinarity & & $\begin{array}{l}\text { Was the appropriate expertise in terms of relevant disci- } \\
\text { plines applied when producing the knowledge? Can } \\
\text { stakeholder knowledge be integrated? The aim is to pro- } \\
\text { gress from multi- to inter- to transdisciplinary science. See } \\
\text { Stakeholder Involvement. }\end{array}$ \\
\hline $\begin{array}{l}\text { Stakeholder } \\
\text { involvement }\end{array}$ & & $\begin{array}{l}\text { Science could benefit from knowledge available with } \\
\text { other stakeholders, notably the business sector. Stake- } \\
\text { holders can play a role in providing knowledge (see 'Use } \\
\text { of Scientific Knowledge') collecting data (monitoring; } \\
\text { cooperative research). The feedback of stakeholders on } \\
\text { making choices under uncertainty is also important. Reed } \\
\text { (2008) identifies eight best practices that improve the } \\
\text { quality and effectiveness of stakeholder participation. }\end{array}$ \\
\hline $\begin{array}{l}\text { Integrated } \\
\text { management }\end{array}$ & \multirow[t]{2}{*}{ Management } & $\begin{array}{l}\text { In this context integrated can be interpreted as cross- } \\
\text { sectoral, inter-disciplinary and/or holistic (i.e., } \\
\text { encompassing the whole SES). Which of these (or other) } \\
\text { perspectives are incorporated into the management pro- } \\
\text { cess? Compliance of the SES aspect Human activities and } \\
\text { their pressures is a requirement. The Decision-making } \\
\text { across administrative boundaries is tightly linked to the } \\
\text { Distinct boundaries criterion where jurisdictional bound- } \\
\text { aries may be different from ecosystem boundaries. Build- } \\
\text { ing resilience requires a governance capable of balancing } \\
\text { heterogeneity, redundancy, modularity and connectivity at } \\
\text { Appropriate temporal and spatial scales (Elmhirst et al. } \\
\text { 2009; Levin et al. 2013) }\end{array}$ \\
\hline $\begin{array}{l}\text { Adaptive } \\
\text { management }\end{array}$ & & $\begin{array}{l}\text { The management should be adaptive as it needs to deal } \\
\text { with the inherent uncertainty of EBM. Learning-by-doing } \\
\text { is needed when outcomes of decisions are uncertain } \\
\text { because of complex system dynamics. This is linked to } \\
\text { ecological EBM criteria: Acknowledge uncertainty, } \\
\text { Account for dynamic nature of ecosystems and }\end{array}$ \\
\hline
\end{tabular}


Table 2 (continued)

\begin{tabular}{|c|c|c|}
\hline EBM criteria & Actors & Generic assessment guidance and considerations \\
\hline & & $\begin{array}{l}\text { Appropriate monitoring. Rather than choosing optimal } \\
\text { paths and decision rules in a deterministic framework, } \\
\text { facing current risks and considerable uncertainties requires } \\
\text { governance frameworks able to adapt to the multiple cir- } \\
\text { cumstances that may prevail in the foreseeable future. }\end{array}$ \\
\hline $\begin{array}{l}\text { Apply the precau- } \\
\text { tionary approach }\end{array}$ & & $\begin{array}{l}\text { Does the institutional set-up allow the application of the } \\
\text { precautionary approach? This requires compliance to the } \\
\text { SES aspect Changes and Uncertainty. }\end{array}$ \\
\hline $\begin{array}{l}\text { Stakeholder } \\
\text { involvement }\end{array}$ & & $\begin{array}{l}\text { Managers depend on the input from science but could } \\
\text { benefit from knowledge available with other stakeholders, } \\
\text { notably the business sector. Also, the feedback of stake- } \\
\text { holders on making choices (or co-decision making) under } \\
\text { uncertainty is important. As compliance of the SES aspect } \\
\text { is a requirement; stakeholder involvement in policy } \\
\text { implementation can be instrumental. }\end{array}$ \\
\hline $\begin{array}{l}\text { Appropriate } \\
\text { monitoring }\end{array}$ & & $\begin{array}{l}\text { A requirement of Adaptive management is adequate } \\
\text { monitoring. The quality of the monitoring is reflected in } \\
\text { the proportion of the relevant components of the SES for } \\
\text { which sufficient data is collected at appropriate spatio- } \\
\text { temporal scale and the level of uncertainty to allow sci- } \\
\text { entific knowledge to guide informed decision-making. } \\
\text { Monitoring programs can be developed in collaboration } \\
\text { with the other stakeholders, i.e. multi-sector actor resulting } \\
\text { in cooperative research. } \\
\text { The monitoring data should be transformed into salient } \\
\text { and legitimate scientific knowledge to guide informed } \\
\text { decision-making. The degree to which that actually occurs } \\
\text { needs to increase in order to advance EBM. }\end{array}$ \\
\hline $\begin{array}{l}\text { Decisions reflect } \\
\text { societal choice }\end{array}$ & $\begin{array}{l}\text { Policy } \\
\text { making }\end{array}$ & $\begin{array}{l}\text { Specifying clear goals increases efficiency and efficacy of } \\
\text { the MSP process and allows the identification of potential } \\
\text { trade-offs of proposed management strategies. Specify } \\
\text { what trade-offs should be considered, e.g. amongst stake- } \\
\text { holders, or between short- and longer-term benefits. } \\
\text { 'Stakeholder involvement' is required specifically in order } \\
\text { to make decision-making inclusive and reflect societal } \\
\text { choice (i.e., legitimacy). }\end{array}$ \\
\hline $\begin{array}{l}\text { Stakeholder } \\
\text { involvement }\end{array}$ & & $\begin{array}{l}\text { For rationale see Röckmann et al. (2015). Check if the } \\
\text { 'typology of eight levels of participation' (Reed 2008) is } \\
\text { applied. The degree of stakeholder interaction should be } \\
\text { appropriate for the specific context. Also, the feedback of } \\
\text { stakeholders on making choices (or co-decision making) } \\
\text { under uncertainty is important. Is there information on } \\
\text { compliance? Stakeholder involvement in decision making } \\
\text { can be instrumental to ascertain compliance. }\end{array}$ \\
\hline Sustainability & & $\begin{array}{l}\text { All three pillars of sustainability (i.e., ecological, eco- } \\
\text { nomic and social) should be considered in the trade-offs } \\
\text { informing the decision-making process. }\end{array}$ \\
\hline $\begin{array}{l}\text { Stakeholder } \\
\text { involvement }\end{array}$ & $\begin{array}{l}\text { All resource } \\
\text { users }\end{array}$ & $\begin{array}{l}\text { The participation and involvement of all the resource users } \\
\text { is the backbone of a successful EBM process. This may be }\end{array}$ \\
\hline
\end{tabular}


Table 2 (continued)

\begin{tabular}{l|l|l}
\hline EBM criteria & Actors & Generic assessment guidance and considerations \\
\hline \multirow{5}{*}{} & $\begin{array}{l}\text { through a top-down process initiated by the government or } \\
\text { a bottom-up process where the users self-organize. In case } \\
\text { of a top-down process stakeholder participation should } \\
\text { reflect and be based on all sectors which are affected by the } \\
\text { plan, local community actors and environmental } \\
\text { non-governmental organizations (NGOs) in addition to the } \\
\text { stakeholder groups specifically mentioned (i.e., science, } \\
\text { policy makers and managers). This to ascertain all relevant } \\
\text { societal claims, values and relevant aspects and impacts } \\
\text { can be considered in the process and involved at each } \\
\text { stage and that implementation and monitoring of strategies } \\
\text { are effectively done. } \\
\text { The likelihood of self-organization of the users to achieve } \\
\text { a sustainable SES was found to depend on several aspects } \\
\text { of the SES covered by the other EBM criteria, see (Ostrom } \\
\text { 2009). }\end{array}$ \\
\hline
\end{tabular}

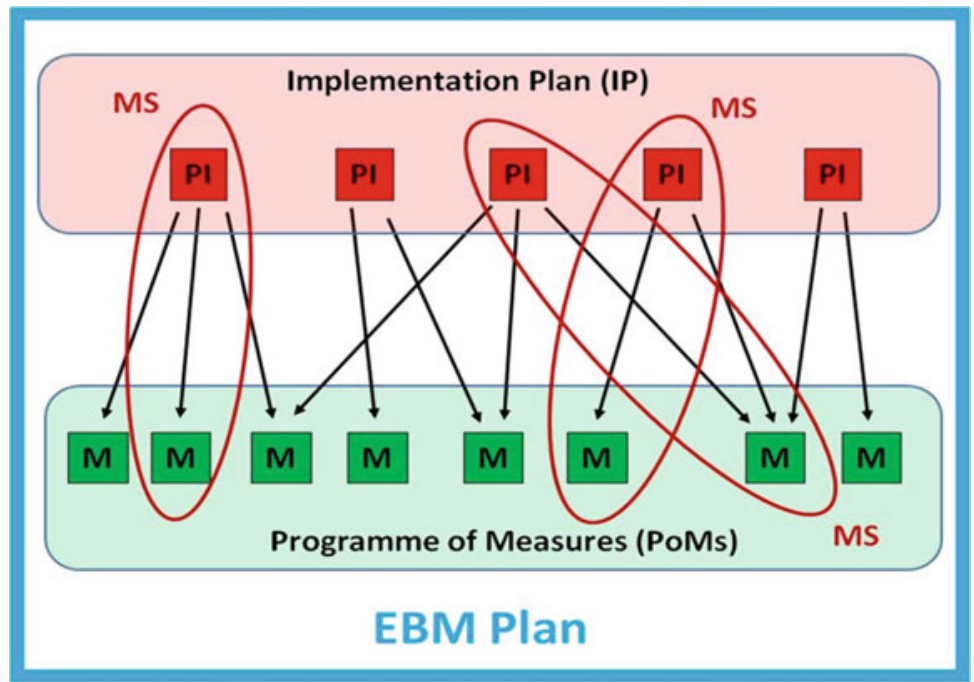

Fig. 3 Diagram explaining the elements that make up an ecosystem-based management plan. $\mathrm{PI}=$ Policy Instruments, $\mathrm{M}=$ Management Measure, $\mathrm{MS}=$ Management Strategy

prevent the pressure from entering the system (e.g., catch controls in fisheries) or spatial- and/or temporal distribution controls (e.g., marine protected areas or real-time closures).

- Mitigation and recovery controls are implemented to reduce the likelihood and magnitude of each consequence as a result of the risk event occurring. We distinguish mitigation controls that target the pressure once it is present in the system (e.g., beach cleaning after oil spills) and recovery controls targeting the 
ecosystem component (state) that is impacted (e.g., habitat restoration or stocking programs). For both mitigation controls there may be a lag in the response depending on the persistence of the pressure or the resilience of the species. For recovery controls, the lag is only determined by the resilience. The choice of the type of management measure thus determines the time horizon when results can be expected.

- Policy instruments are integrated into an Implementation Plan. This consists of all the arrangements or reforms that are required in the governing system (as part of the social system) for the implementation of the Programme of Measures and the overall performance of the full EBM plan. The following types of policy instruments can be distinguished (see Lago et al. 2015; FrelihLarsen et al. 2016):

- Legislative instruments, including various (inter)national conservation laws or regulations

- Regulatory instruments, including the setting of targets or standards aimed at maintaining a certain level of environmental quality, prohibits (i.e., bans) or allows (i.e., permits) an individual or business to perform certain acts, or to have a certain portion (or amount) of a product

- Economic instruments such as pricing mechanisms (e.g., tariffs, taxes and charges, trading of permits), payments, or liability schemes

- Instruments involving information, awareness-raising, and public engagement such as training and qualifications (e.g., obtaining certificates or proof of qualification) related to environmental protection, public information programs, stakeholder and public participation, or innovation groups that aim to build capacity and knowledge about a particular environmental, economic, or practical issue

- 'Nudges' are possible alternatives to the instruments mentioned above, whereby the behaviour of actors (e.g., industry, civilians) is influenced (or nudged) towards the preferred choice via positive reinforcement and indirect suggestions such as changing the default option in a form (Valatin et al. 2016)

- Monitoring and research aimed at improving the SES knowledge base. This may include the collecting of additional data or developing an understanding on specific gaps that may correspond to specific nodes or linkages in the linkage framework that hampered this EBM cycle but may be useful in the next EBM cycle.

The design step of the EBM plan commences with the selection of appropriate candidate management measures. This is guided by the ERA, which identifies the linkages contributing most to environmental impact risk indicating the potential management measures following the approach developed by Piet et al. (2015). Those candidate management measures should cover all the major threats and are considered most likely to reduce the environmental impact risk. A pre-screening exercise using the '10-tenets of adaptive management' (Barnard and Elliott 2015) may be conducted to ascertain a priori that all possible issues are considered that may prevent the success of management measures or policy instruments. Failure to comply to any one of the tenets should be reason to re-consider a particular management measures or policy instrument. By applying these tenets as screening 
criteria for the list of potential issues, those issues that do not tie directly to a tenet, should be removed from further testing in the evaluation step.

In this evaluation step, the future performance of an alternative EBM plan is compared to that of the existing (e.g. baseline, business-as-usual) management plan. Both the alternative and baseline management plans may result in different outcomes depending on exogenous drivers (e.g., socio-economic or climate scenarios). For the evaluation of the alternative EBM plan(s) against baseline, we propose three outcome-oriented criteria:

- Effectiveness: Does the plan achieve the pre-determined target? This is what usually constitutes effective evaluation of a management strategy (see Punt et al. 2016 for best practices) and involves the simulation of specific indicator trajectories with their error distributions relative to policy targets (e.g. fishing mortality indicator relative to the target of Maximum Sustainable Yield). Effectiveness of an individual measure, or of a programme of measures, along with its implementation plan, is defined by the contribution it makes to bridge the information gap between understanding baseline conditions and target conditions.

- Efficiency: Is the plan conducive to enhance human wellbeing? This refers to the capacity of citizens and social institutions to take advantage of existing opportunities (as determined by technology, resource endowments and actual availability, physical and human capital, etc.) to improve human wellbeing in a sustainable way. It is a concept that applies to the users of a particular service (i.e., those who may have the opportunity to utilise the service without making anyone else worse off), the stakeholders in a particular decision context (i.e., who may have the option to cooperate in the preservation of a resource and share the benefits amongst them), or the government (i.e., who may have the possibility of improving the environment without worsening opportunities in terms of economic activities). This criterion is ultimately an assessment of sustainable development, where each generation should aim at improving its wellbeing within the available opportunities as long as this does not compromise the options available to future generations. The benefits and costs are defined as any positive or negative impacts on human wellbeing, irrespective of whether the affected individuals are aware of them, or whether they can be valued through market prices or any other ad-hoc valuation exercise. When comparing benefits and costs, the issue is that costs are often monetised and are relatively certain, whereas benefits may be difficult to monetise and are definitely more uncertain (though mostly just as real).

- Equity: Are the benefits being shared in a socially just way? The distribution of benefits and costs across stakeholders must be perceived as fair. Besides the contribution of the EBM plan, to social equity, the legitimacy of the EBM plan requires the perception that its consequences are fairly distributed among the affected parties both in the present as well as the future (i.e., intergenerational equity). 


\subsection{Phase IV: Implementation, Monitoring and Evaluation}

This is the phase where EBM becomes operational based on the planning in the previous phases. According to Cormier et al. (2017), it is the competent authorities of specific sectors that are accountable to implement the measures that are designed to manage their specific operations. The role of science is to: (1) inform those sectorspecific authorities on the detail of the measures before implementation; as well as (2) design the monitoring programs; and (3) conduct and inform the subsequent evaluation of the performance of those measures after implementation. The performance is evaluated testing indicators against a benchmark as a measure of achieving an objective. When the benchmark is not met, the goals and objectives needs to be re-examined and/or the management regime re-assessed (Behn 2003; Poister et al. 2010) in phases I and III of the next EBM cycle.

While a monitoring program is primarily intended to assess the status of the SES and the performance of the EBM plan, it can also feed relevant information into the knowledge base and hence need to be aligned with system-oriented criteria of Table 1. The implementation of any future alternative EBM plan is determined by the governance context and the institutional processes captured in the Phase II knowledge base with the process-oriented criteria in Table 2. The performance of the EBM plan can then be used to guide the planning (Phase III) in the next EBM cycle, which builds on the previous EBM plan by adopting those management measures or policy instruments that performed well, and modifying or replacing those that failed. Incorporating the feedbacks from Phase IV and integrating it into the next EBM cycle is crucial to a successful EBM process.

\section{Discussion and Conclusions}

The EBM approach presented here is an attempt to combine or reconcile many existing concepts that describe the ecological system, the social (or socio-economic) system and EBM into a unifying approach with guidance on how to make it (more) operational in any aquatic ecosystem based on a diverse existing literature incorporating concepts from IEA, Marine Spatial Planning, ERA, resilience and CAS (Long et al. 2015; Cormier et al. 2017; Levin et al. 2009b; Samhouri et al. 2014; Levin et al. 2009b; Samhouri et al. 2014; Ansong et al. 2017; Folke et al. 2010; Hagstrom and Levin 2017). We have attempted to translate these concepts into concrete steps, identify issues for the practitioner to consider, give examples that provide the basis for a common framework, and suggest practical guidance for the incorporation and synthesis of interdisciplinary information on SES into practical and useful linkage frameworks for EBM plan development and implementation. One example of a practical application of this framework can be found in (Piet et al. 2019).

Integrated ERAs have been included in environmental impact assessments for many decades but it was not until the work of Halpern et al. (2008) that the 
cumulative effects of multiple stressors received much attention. Since then, many other such integrated assessments have taken place in marine waters (e.g., Coll et al. 2012; Knights et al. 2013; Korpinen et al. 2012) and are now also covering inland and transitional waters (e.g., Borgwardt et al. 2019). These integrated assessments all apply different methodologies which may differ on their ability to inform EBM and associated monitoring requirements (Borja et al. 2016). Even within a specific integrated assessment there are methodological choices to be made depending on the chosen subSES and/or the application of the ERA (Piet et al. 2017).

The EBM process consisting of four phases (I-IV) has been built around the SES concept that brings together the natural and social scientific disciplines involved in EBM. The contribution of this study to advance EBM occurs primarily in Phase II and Phase III. Advancements in Phase II consists of: (1) approaches to reduce a complex suite of SES to one or more focused subSES to avoid inaction from overwhelming complexity, a common problem when resolving wicked problems such as EBM; and (2) practical guidance based on key EBM principles (Long et al. 2015) involving both the ecological system as well as the social system. Advancements in Phase III consists of the organizing the structure and typology of an EBM plan that is explicitly linked to both the ecological system as well as the social system. Even though the findings of this study are primarily relevant for the science domain, it explicitly acknowledges the interaction with wider society. This approach structurally incorporates consultation with other stakeholder groups in order to enhance the credibility in knowledge production and ascertain salient scientific input in the domain of policy-makers, decision-makers, and managers (Röckmann et al. 2015).

Despite the many issues that are still unresolved, this study provides the theoretical and conceptual basis to apply some of the methodological studies in this volume (Borgwardt et al. 2019; Teixeira et al. 2019) in order to advance the implementation of EBM toward and achievement of policy objectives in support of the societal goals for our aquatic systems (see Piet et al. 2019).

Acknowledgement This project is part of the AQUACROSS project (Knowledge, Assessment, and Management for AQUAtic Biodiversity and Ecosystem Services aCROSS EU policies) funded by the European Union's Horizon 2020 research and innovation programme under grant agreement No 642317.

\section{References}

Aanesen, M., Armstrong, C. W., Bloomfield, H. J., \& Röckmann, C. (2014). What does stakeholder involvement mean for fisheries management? Ecology and Society, 19(4), 35.

Ansong, J., Gissi, E., \& Calado, H. (2017). An approach to ecosystem-based management in maritime spatial planning process. Ocean \& Coastal Management, 141, 65-81.

Barnard, S., \& Elliott, M. (2015). The 10-tenets of adaptive management and sustainability: An holistic framework for understanding and managing the socio-ecological system. Environmental Science \& Policy, 51, 181-191. 
Behn, R. D. (2003). Why measure performance? Different purposes require different measures. Public Administration Review, 63, 586-606.

Berkes, F. (2012). Implementing ecosystem-based management: Evolution or revolution? Fish and Fisheries, 13, 465-476.

Bianchi, G. (2008). The concept of the ecosystem approach to fisheries. In G. Bianchi (Ed.), FAO the ecosystem approach to fisheries (pp. 20-38, Chap. 2). Oxfordshire: CABI.

Biggs, R., Schlüter, M., \& Schoon, M. L. (2015). Principles for building resilience: Sustaining ecosystem services in social-ecological systems (pp. 1-290).

Bissix, G., \& Rees, J. A. (2001). Can strategic ecosystem management succeed in multiagency environments? Ecological Applications, 11, 570-583.

Borgström, S., Bodin, Ö., Sandström, A., \& Crona, B. (2015). Developing an analytical framework for assessing progress toward ecosystem-based management. Ambio, 44, 357-369.

Borgwardt, F., Robinson, L., Trauner, D., Teixeira, H., Nogueira, A. J., Lillebø, A., Piet, G., Kuemmerlen, M., O’Higgins, T., McDonald, H., Arevalo-Torres, J., Barbosa, A. L., IglesiasCampos, A., Hein, T., \& Culhane, F. (2019). Exploring variability in environmental impact risk from human activities across aquatic realms. Science of the Total Environment, 652, 1396-1408.

Borja, A., Elliott, M., Andersen, J. H., Berg, T., Carstensen, J., Halpern, B. S., Heiskanen, A.-S., et al. (2016). Overview of integrative assessment of marine systems: The ecosystem approach in practice. Frontiers in Marine Science, 3, 20.

Christie, P. (2011). Creating space for interdisciplinary marine and coastal research: Five dilemmas and suggested resolutions. Environmental Conservation, 38, 172-186.

Coll, M., Piroddi, C., Albouy, C., Lasram, F. B., Cheung, W. W. L., Christensen, V., Karpouzi, V. S., et al. (2012). The Mediterranean Sea under siege: Spatial overlap between marine biodiversity, cumulative threats and marine reserves. Global Ecology and Biogeography, 21, 465-480.

Cormier, R., Kannen, A., Elliott, M., Hall, P., \& Davies, I. M. (2013). Marine and coastal ecosystem-based risk management handbook. ICES Cooperative Research Report No. 317. $60 \mathrm{pp}$.

Cormier, R., Kelble, C. R., Anderson, M. R., Allen, J. I., Grehan, A., \& Gregersen, O. (2017). Moving from ecosystem-based policy objectives to operational implementation of ecosystembased management measures. ICES Journal of Marine Science, 74, 406-413.

Cormier, R., Elliott, M., \& Kannen, A. (2018). IEC/ISO Bow-tie analysis of marine legislation: A case study of the marine strategy framework directive. ICES Cooperative Research.

Crain, C. M., Kroeker, K., \& Halpern, B. S. (2008). Interactive and cumulative effects of multiple human stressors in marine systems. Ecology Letters, 11, 1304-1315.

Culhane, F., Teixeira, H., Nogueira, A. J., Borgwardt, F., Trauner, D., Lillebø, A., Piet, G., Kuemmerlen, M., McDonald, H., O'Higgins, T., \& Barbosa, A. L. (2019). Risk to the supply of ecosystem services across aquatic ecosystems. Science of the Total Environment, 660, 611-621.

DeFries, R., \& Nagendra, H. (2017). Ecosystem management as a wicked problem. Science, 356, 265.

De Lange, H. J., Sala, S., Vighi, M., \& Faber, J. H. (2010). Ecological vulnerability in risk assessment - A review and perspectives. Science of the Total Environment, 408, 3871-3879.

Dick, J., Turkelboom, F., et al. (2017). Stakeholders' perspectives on the operationalisation of the ecosystem service concept: Results from 27 case studies. Ecosystem Services.

Dietz, T., Ostrom, E., \& Stern, P. C. (2003). The struggle to govern the commons. Science, 302, $1907-1912$

EEA. (1995). Europe's environment: The Dobris assessment. European Environmental Agency, $8 \mathrm{pp}$.

Elliott, M. (2002). The role of the DPSIR approach and conceptual models in marine environmental management: An example for offshore wind power. Marine Pollution Bulletin, 44: III-VII. 
Elliott, M., Burdon, D., Atkins, J. P., Borja, A., Cormier, R., de Jonge, V. N., \& Turner, R. K. (2017). "And DPSIR begat DAPSI(W)R(M) !" - A unifying framework for marine environmental management. Marine Pollution Bulletin, 118, 27-40.

Elmhirst, T., Connolly, S. R., \& Hughes, T. P. (2009). Connectivity, regime shifts and the resilience of coral reefs. Coral Reefs, 28, 949-957.

Folke, C., Hahn, T., Olsson, P., \& Norberg, J. (2005). Adaptive governance of social-ecological systems. Annual Review of Environment and Resources, 30, 441-473.

Folke, C., Carpenter, S. R., Walker, B., Scheffer, M., Chapin, T., \& Rockström, J. (2010). Resilience thinking: Integrating resilience, adaptability and transformability. Ecology and Society, 15(4). https://doi.org/10.5751/ES-03610-150420.

Frelih-Larsen, A., Bowyer, C., Albrecht, S., Keenleyside, C., Kemper, M., Nanni, S., et al. (2016). Updated inventory and assessment of soil protection policy instruments in EU member states. Final Report to DG Environment. Berlin: Ecologic Institute.

Gómez, C. M., Delacámara, G., Arevalo-Torres, J., Barbiere, J., Barbosa, A.L., \& Iglesias-Campos, A. (2016). The AQUACROSS innovative concept. Deliverable 3.1, European Union's Horizon 2020 Framework Programme for Research and Innovation Grant Agreement No. 642317.

Hagstrom, G. I., \& Levin, S. A. (2017). Marine ecosystems as complex adaptive systems: Emergent patterns, critical transitions, and public goods. Ecosystems, 20, 458-476.

Halpern, B. S., Walbridge, S., Selkoe, K. A., Kappel, C. V., Micheli, F., D’Agrosa, C., Bruno, J. F., et al. (2008). A global map of human impact on marine ecosystems. Science, 319, 948-952.

Harvey, C. J., Kelble, C. R., \& Schwing, F. B. (2017). Implementing "the IEA": Using integrated ecosystem assessment frameworks, programs, and applications in support of operationalizing ecosystem-based management. ICES Journal of Marine Science, 74, 398-405.

Hobday, A. J., Smith, A. D. M., Stobutzki, I. C., Bulman, C., Daley, R., Dambacher, J. M., Deng, R. A., et al. (2011). Ecological risk assessment for the effects of fishing. Fisheries Research, $108,372-384$.

Holsman, K., Samhouri, J., Cook, G., Hazen, E., Olsen, E., Dillard, M., Kasperski, S., Gaichas, S., Kelble, C. R., Fogarty, M., \& Andrews, K. (2017). An ecosystem-based approach to marine risk assessment. Ecosystem Health and Sustainability, 3(1), e01256. https://doi.org/10.1002/ehs2. 1256.

ICES. (2017). WKBESIO: Report of the WorKshop on balancing economic, social, and institutional objectives in integrated assessments.

Katsanevakis, S., Stelzenmuller, V., South, A., Sorensen, T. K., Jones, P. J. S., Kerr, S., Badalamenti, F., et al. (2011). Ecosystem-based marine spatial management: Review of concepts, policies, tools, and critical issues. Ocean \& Coastal Management, 54, 807-820.

Knights, A. M., Koss, R. S., \& Robinson, L. A. (2013). Identifying common pressure pathways from a complex network of human activities to support ecosystem-based management. Ecological Applications, 23, 755-765.

Knights, A. M., Culhane, F., Hussain, S. S., Papadopoulou, K. N., Piet, G. J., Raakaer, J., Rogers, S. I., et al. (2014). A step-wise process of decision-making under uncertainty when implementing environmental policy. Environmental Science \& Policy, 39, 56-64.

Knights, A. M., Piet, G. J., Jongbloed, R. H., Tamis, J. E., White, L., Akoglu, E., Boicenco, L., et al. (2015). An exposure-effect approach for evaluating ecosystem-wide risks from human activities. ICES Journal of Marine Science, 72, 1105-1115.

Korpinen, S., Meski, L., Andersen, J. H., \& Laamanen, M. (2012). Human pressures and their potential impact on the Baltic Sea ecosystem. Ecological Indicators, 15, 105-114.

Lago, M., Mysiak, J., Gomez, C. M., Delacamara, G., \& Maziotis A. (Eds.). (2015, October). Use of economic instruments in water management - Insights from international experience. Cham: Springer.

Levin, P. S., Fogarty, M. J., Murawski, S. A., \& Fluharty, D. (2009a). Integrated ecosystem assessments: Developing the scientific basis for ecosystem-based management of the ocean. PLoS Biology, 7, 23-28. 
Levin, P. S., Fogarty, M. J., Murawski, S. A., \& Fluharty, D. (2009b). Integrated ecosystem assessments: Developing the scientific basis for ecosystem-based management of the ocean (perspective). PLoS Biology, 7, e1000014.

Levin, S., Xepapadeas, T., Crépin, A. S., Norberg, J., De Zeeuw, A., Folke, C., Hughes, T., et al. (2013). Social-ecological systems as complex adaptive systems: Modeling and policy implications. Environment and Development Economics, 18, 111-132.

Levin, P. S., Kelble, C. R., Shuford, R. L., Ainsworth, C., deReynier, Y., Dunsmore, R., Fogarty, M. J., et al. (2014). Guidance for implementation of integrated ecosystem assessments: A US perspective. ICES Journal of Marine Science, 71, 1198-1204.

Long, R. D., Charles, A., \& Stephenson, R. L. (2015). Key principles of marine ecosystem-based management. Marine Policy, 57, 53-60.

Ludwig, D. (2001). The era of management is over. Ecosystems, 4, 758-764.

Nelson, G. C., Bennett, E., Berhe, A. A., Cassman, K., DeFries, R., Dietz, T., Dobermann, A., et al. (2006). Anthropogenic drivers of ecosystem change: An overview. Ecology and Society, 11, 29.

OECD. (1994). Environmental indicators: OECD Core set. Paris: Organisation for Economic Co-operation and Development.

Ostrom, E. (2009). A general framework for analyzing sustainability of social-ecological systems. Science, 325, 419-422.

Piet, G. J., Jongbloed, R. H., Knights, A. M., Tamis, J. E., Paijmans, A. J., van der Sluis, M. T., de Vries, P., et al. (2015). Evaluation of ecosystem-based marine management strategies based on risk assessment. Biological Conservation, 186, 158-166.

Piet, G. J., Knights, A. M., Jongbloed, R. H., Tamis, J. E., de Vries, P., \& Robinson, L. A. (2017). Ecological risk assessments to guide decision-making: Methodology matters. Environmental Science \& Policy, 68, 1-9.

Piet, G., Culhane, F., Jongbloed, R., Robinson, L., Rumes, B., \& Tamis, J. (2019). An integrated risk-based assessment of the North Sea to guide ecosystem-based management. Science of the Total Environment, 654, 694-704.

Poister, T. H., Pitts, D. W., \& Edwards, L. H. (2010). Strategic management research in the public sector: A review, synthesis, and future directions. American Review of Public Administration, $40,522-545$.

Polasky, S., de Zeeuw, A., \& Wagener, F. (2011). Optimal management with potential regime shifts. Journal of Environmental Economics and Management, 62, 229-240.

Punt, A. E., Butterworth, D. S., de Moor, C. L., de Oliveira, J. A. A., \& Haddon, M. (2016). Management strategy evaluation: Best practices. Fish and Fisheries, 17, 303-334.

Rademeyer, R. A., Plaganyi, E. E., \& Butterworth, D. S. (2007). Tips and tricks in designing management procedures. ICES Journal of Marine Science, 64, 618-625.

Reed, M. S. (2008). Stakeholder participation for environmental management: A literature review. Biological Conservation, 141, 2417-2431.

Rittel, H. W. J., \& Webber, M. M. (1973). Dilemmas in a general theory of planning. Policy Sciences, 4(2), 155-169.

Röckmann, C., van Leeuwen, J., Goldsborough, D., Kraan, M., \& Piet, G. (2015). The interaction triangle as a tool for understanding stakeholder interactions in marine ecosystem based management. Marine Policy, 52, 155-162.

Ruckelshaus, M., Essington, T., \& Levin, P. (2009). Puget Sound, Washington, USA. In K. M. H. Leslie (Ed.), Ecosystem-based management for the oceans (pp. 201-226). Washington, DC: Island Press.

Samhouri, J. F., Haupt, A. J., Levin, P. S., Link, J. S., \& Shuford, R. (2014). Lessons learned from developing integrated ecosystem assessments to inform marine ecosystem-based management in the USA. ICES Journal of Marine Science, 71, 1205-1215.

Stelzenmüller, V., Fock, H. O., Gimpel, A., Rambo, H., Diekmann, R., Probst, W. N., Callies, U., et al. (2015). Quantitative environmental risk assessments in the context of marine spatial 
management: Current approaches and some perspectives. ICES Journal of Marine Science, 72, $1022-1042$

Tallis, H., Levin, P. S., Ruckelshaus, M., Lester, S. E., McLeod, K. L., Fluharty, D. L., \& Halpern, B. S. (2010). The many faces of ecosystem-based management: Making the process work today in real places. Marine Policy, 34, 340-348.

Teixeira, H., Lillebø, A. I., Culhane, F., Robinson, L., Trauner, D., Borgwardt, F., Kummerlen, M., Barbosa, A., McDonald, H., Funk, A., \& O'Higgins, T. (2019). Linking biodiversity to ecosystem services supply: Patterns across aquatic ecosystems. Science of the Total Environment, 657, 517-524.

Turkelboom, F., Leone, M., et al. (2017). When we cannot have it all: Ecosystem services trade-offs in the context of spatial planning. Ecosystem Services.

Valatin, G., Moseley, D., \& Dandy, N. (2016). Insights from behavioural economics for forest economics and environmental policy: Potential nudges to encourage woodland creation for climate change mitigation and adaptation? Forest Policy and Economics, 72, 27-36.

Walther, Y. M., \& Möllmann, C. (2014). Bringing integrated ecosystem assessments to real life: A scientific framework for ICES. ICES Journal of Marine Science, 71, 1183-1186.

Open Access This chapter is licensed under the terms of the Creative Commons Attribution 4.0 International License (http://creativecommons.org/licenses/by/4.0/), which permits use, sharing, adaptation, distribution and reproduction in any medium or format, as long as you give appropriate credit to the original author(s) and the source, provide a link to the Creative Commons licence and indicate if changes were made.

The images or other third party material in this chapter are included in the chapter's Creative Commons licence, unless indicated otherwise in a credit line to the material. If material is not included in the chapter's Creative Commons licence and your intended use is not permitted by statutory regulation or exceeds the permitted use, you will need to obtain permission directly from the copyright holder.

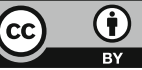

